\title{
Hungry Ghosts: The Impact of Food as a Workplace Health Concern among University Staff and Faculty
}

\author{
Annie L. Booth' \\ Ecosystem Science and Management Program \\ University of Northern British Columbia, Canada
}

\section{Abstract}

The indoor biome is of growing interest among human ecologists, yet relatively poorly studied at present. Food systems offer one approach to understanding the intersection of human well-being and institutional structures within an indoor ecology case study. This study examines a food system within a Canadian university setting, with particular reference to the issue of food security-the ability of an individual to access sufficient nutritious food for a healthy life-among university faculty and staff. The results suggest that institutional structures affect employee perceptions of their precarious food and nutritional security. While university students have been studied regarding their food security status, university staff and faculty have never been similarly studied. Findings suggest that poor food security levels among staff and faculty lead to challenges in work performance and in the overall well-being of the university as a community. University leaders should take seriously issues of food security among their employees as well as their students.

Keywords: food security, institutional food systems, tertiary institutions, workplace health

How full of briers is this working day world.

William Shakespeare, As You Like It (Act III, scene 2)

\section{Introduction}

Universities are peculiar institutional ecosystems. Their principle reason for existence is to offer advanced education for students, in addition to conducting research. Thus, the most visible members in the university community are students and the faculty who do the teaching and research. Given their critical value to the university, it is not surprising that a considerable amount of research considers the challenges

1 Corresponding author: annie.booth@unbc.ca 
that students face, including poor food security. Rarely acknowledged and never studied in terms of their work challenges or critical contributions to the university community are the university staff, "ghosts" who keep the university running. Faculty, while less invisible than staff, may also find that their workplace challenges are invisible to decision-makers. Neither faculty nor staff have ever been studied with regard to their food security, leaving them not just ghosts but, as this research suggests, hungry ghosts.

Our places of employment can have a significant impact on our health and wellbeing. The United States Center for Disease Control and Prevention observes that "most working-age adults spend a substantial portion of their waking hours in their workplaces" (Goetzel \& Ozminkowski, 2008, p. 305). Some workplaces have a clear, and often direct, impact on worker health due to inherent risks, as for firefighters. Other workplaces offer subtle impacts through institutional structures, cultures or expectations. These impacts can, over time, be as profound as acute health challenges. This study examines Canadian university faculty and staff well-being as measured by their perceptions of the institution's impact on their level of food and nutritional security (subsequently referred to as f\&n security), in other words, their ability to eat in a healthy way. Understanding how a workplace's structures and cultures impact worker well-being is a critical step in implementing actions to improve employee well-being, an important consideration as healthy workers benefit the workplace through increased productivity, commitment to the success of the employer, and money saved through lower use of benefits and less absenteeism (Goetzel \& Ozminkowski, 2008).

Human ecology offers a useful lens for understanding the interrelationships of worker well-being, food systems, and institutions. Dyball and Carlsson (2017, p. 26) note that human ecology explicitly links "the interrelationships between humans, their cultures and their ecosystems." While many such studies focus upon human interactions within natural ecosystems, Stokols (2018) and WakefieldRann and Fam (2018) argue that the most rapidly expanding biome in the world is the indoor environment. Understanding these indoor environments is imperative as "indoor environments can represent atmospheres permeated by hazard and insecurity ... when human needs are miscalculated or inadequately provided for" (Wakefield-Rann \& Fam, 2018, p. 19). People spend substantial hours in indoor environments, including their workplaces, which "amplifies whatever positive or negative effects those settings may have on their health, behavior and development" (Stokols, 2018, p. 27). However, Stokols (2018) notes the relative paucity of studies on indoor environments. Thus, human ecology confirms the importance of critical examination of an "indoor ecosystem," such as a workplace, including its culture and systems services. 
Davila (2018, p. 28) argues that, within human ecological study, food systems are understood as the "interactions between biophysical and human systems that influence all aspects of food activities." He notes that food systems studies are useful frameworks for understanding human ecology, which in turn can offer a useful frame for understanding subtle and sometimes hidden discussions around food activities, including the implications of institutional and political forces for f\&n security as well as the interlinkage of institutions, human well-being, and ecosystems.

\section{Research context}

Universities are rather unique workplaces, opaque to outsiders and often to their own employees. They are highly stratified, with three distinct groups of employees: administrators (who hold decision-making powers), faculty (the most visible employees who teach and do research) and staff (who do everything else from facility maintenance to IT), with subdivisions within those broad categories. Given their rather specific workplace niches, while the different groups work in related ways to support university structures and functions, they are also relatively discrete in their functions (or silos) and often regard each other as quite distinct groups. There are also very clear hierarchical differences in relative power and authority (administrators "on top," followed by faculty and then staff) and related income levels. While some jobs within a university come with direct work-related health risks (e.g., facilities and maintenance or field-based research), overall universities are not generally thought of as high-risk places to work. However, preliminary research on universities is demonstrating that they can be places with significant impacts on employee health, as Parizeau et al. (2016, p. 193) note, "many of our academic institutions do not adequately foster working and learning environments that support wellness."

Institutional cultures and expectations within universities have changed over the last few decades to stress increasing productivity and output (students graduating and research publications), which can come at the expense of the health and well-being of faculty and the staff supporting them:

We experience academic cultures and practices that valorize overwork, including expressions of martyrdom, talking about not sleeping or eating and about working all the time, an expectation of always being available for work purposes, and discussions of having children as a problem for work. (Parizeau et al., 2016, p. 197)

As Mountz (2016, p. 208) describes institutional expectations,

The imagined "ideal worker" is ... able to perform long hours physically and emotionally and unencumbered by "outside demands" like family or personal needs. She is highly efficient and able to operate on sparse amounts of sleep or nourishment. 
As one study concludes, "[faculty] have all encountered insufficient time and energy to prioritize mental and overall wellbeing" (Parizeau et al., 2016, p. 198). A last challenge is often the new nature of university employment in North America where universities increasingly employ poorly paid and usually temporary contract faculty to teach their courses, rather than better paid tenure-track or tenured faculty. Staff are usually paid far less than faculty, and also face high levels of job insecurity.

Thus, as academics turn their gaze inward, their research suggests that institutional structures affect employee health through an institutional culture which emphasizes or only rewards accomplishments that undermine individual goals of work-life balance or genuine workplace well-being. All faculty, speaking from empirical observations, are well aware of these unwritten but quite clear requirements for success, as denoted through jokes, wry observations or outright desperate confessions around the inability to meet work demands and the costs to the individual. However, the limited studies on university workplace wellness cited above are lacking: the few studies that do look at work in universities in relation to wellbeing focus exclusively upon faculty; no studies have been undertaken on the costs of institutional requirements to staff health and well-being.

In considering the measurement of health and/or well-being, one measure of interest is the issue of food security and access to adequate quantities of nutritious food (f\&n security). The growing academic field of food security studies posits the critical aspect of nutrition in understanding individual or population health and well-being. A very basic definition of poor food security is "the inability to access and procure, through conventional avenues, nutritionally adequate foods capable of supporting an active and healthy life" (Micevski et al., 2014, p. 258). Research suggests that there are serious consequences to poor nutrition for the individual and, by extension, to society which must bear the collective costs of these consequences; thus research is beginning to document the nature of f\&n security in different populations (Mammen et al., 2009; Tarasuk et al., 2014, 2016).

McIntyre et al. (2012) note that while Canadian government programs have worked to move people off social assistance and into employment, this has, for many, simply resulted in them becoming "working poor" and remaining food insecure. ${ }^{2}$ Tarasuk et al. (2016) note that in 2014, 12\% of Canadian households reported some level of food insecurity, with just over $8 \%$ either moderately or severely insecure. Many of these households were lower income, including $33.5 \%$ of female-led households with younger children who were food insecure. Tarasuk et al. (2016) also noted a disproportionate number of Aboriginal and visible minorities among the working

2 The terms food security and food insecurity are often used interchangeably. However, food insecurity often refers to the inability to acquire food due to financial challenges, whereas food security may include multiple factors at play. 
food insecure. Material life costs may also be a factor, such as expensive housing or the costs of living (living in colder climates and having higher heating costs, for example) (Mammen et al., 2009).

Woolf et al. (2011) note that choices to eat healthily are critical in contributing to an individual's health and welfare. If good food is unaffordable, inaccessible or marginalized by unhealthy 'fast' foods, people will have their personal choice to eat healthily unavoidably shaped by outside contextual circumstances. Woolf et al. (2011) also make clear that all efforts to educate or counsel better choices for health will have little effect under these circumstances, noting that health initiatives require partnerships and linkages between major players in an individual's life, such as linking home, work, and community.

Poor access to healthy food creates serious consequences for an individual, including "poorer physical and mental health and higher rates of chronic conditions, including depression, diabetes and heart disease" (Tarasuk et al., 2014, p. 5). However, the costs of low food security are more than physical; they can affect mental and emotional well-being (Williams et al., 2012). For some people, including some of this study's participants, struggling to obtain food is a critical dimension, but struggling with institutional structures controlling access to food while feeling judged by those institutions for needing aid is worse (this study demonstrated that, for some, solutions to poor food security required anonymity, suggesting a fear of judgment by others in the workplace).

Universities are becoming key populations studied regarding food security; however, all such studies focus upon university or college students (Cady, 2014; Canadian Federation of Students-Ontario, 2012; Chaparro et al., 2009; El Zein, 2017; Farahbakhsh et al., 2015; Frank, 2018; Gaines et al., 2014; Hanna, 2014; Hughes et al., 2011; Martinez et al., 2018; McArthur et al., 2018; Meldrum \& Willows, 2006; Micevski et al., 2014; Munro et al., 2013; Patton-Lopez et al., 2014; Payne-Sturges et al., 2018; Watson et al., 2017). What is not studied are the correlate levels of food security experienced by the other members of the post-secondary 'community': staff and faculty.

This research gap is likely due to an assumption that, with regular employment options and, in the cases of some faculty although not necessarily staff, above national median salaries, access to healthy food is not a concern. However, when the issue of food is examined through a lens of workplace institutional structures and cultures and the link to well-being, this assumption is called into question. The nature of the university as a place or an institutional ecology, as noted above, comes with specific structures that challenge a worker's ability to maintain well-being, including healthy eating. There are other considerations suggesting a need to investigate the issue of food as an indicator of well-being among staff and faculty: while poor food 
security is often linked with financial insecurity, many circumstances can contribute to poor food security, even among relatively well-paid faculty, through workplace expectations or culture.

There is one last consideration: whether universities, as employers, should have as an operational expectation the ethical imperative to consider the well-being of their employees. While they are employers in much the same way as any other place of business, universities are considered to have a special role within society that is quite different than other workplaces. They are generally expected to be ethical leaders, modeling such ethics for the benefit of the students within their walls (Seligsohn, 2016). Indeed, their exceptional position as critical social leaders places upon universities a greater burden of modeling ethical practices, observable internally and externally (Duke, 2019; McNay, 2019). There may well be an ethical imperative to model consideration for the health and well-being of their employees as part of their institutional ecology, even when the society within which a university sits does not.

\section{Methodology}

\section{The case study community}

This project assessed issues related to f\&n security at the University of Northern British Columbia (UNBC), a small university located in Prince George, British Columbia, Canada (est. 1990). In 2015, as a component of the development of a campus-wide food strategy by UNBC's Office of Sustainability (which was never completed), the author was asked to undertake research into the issue of campus food quality and access as well as personal factors affecting food concerns and potential institutional responses. The project took a community f\&n security approach, investigating the issues at an institutional level through inclusion of all community members: staff, faculty, and students (see Booth and Anderson (2017) for a broad overview of the study findings). This article specifically examines the self-assessment of their level of f\&n security by UNBC's staff and faculty. The research project explicitly did not meet the current requirements of academic food security studies, as it did not utilize validated research instruments such as the Household Food Security Survey Module utilized by Statistics Canada. Rather, the research model had to meet several investigatory needs outside of food security studies, including perceptions of the food services provider and recommendations for campus food options. However, as this research illuminates the issue of f\&n security as it relates to workplace structures, cultures, and worker well-being in a never-before studied population, the findings may nonetheless be of interest. 
UNBC employs a substantial number of faculty, including tenured, tenure-track, senior laboratory instructors, and contract faculty as well as non-union librarians. ${ }^{3}$ As of September 2015, the UNBC Faculty Association reported 343 members (personal communication, September 15, 2015). UNBC also employs staff in a wide variety of positions. Most are members of the Canadian Union of Public Employees (CUPE), a few others belong to an Exempt group (exempt from union membership, quasi-managerial positions). As of September 2015, 392 staff were employed at UNBC (personal communications, CUPE president, September 15, 2015; Exempt group head, September 16, 2015).

As a workplace ecosystem, UNBC shares some institutional structures linked in the research literature with food concerns among students, including a location isolated from non-university businesses such as grocery stores (Canadian Federation of Students-Ontario, 2012). As well, UNBC has contracted with a for-profit company for campus food services, which has an exclusionary lock on food services with the exception of a student-run pub serving lunch. These exclusionary rights limit outside food being brought on to campus for community events, as well as restricting competing food sales. During summer operations, however, food service becomes quite restricted as the student pub closes and only one outlet offers deli and coffee shop foods; this does not operate on weekends or in the evening in the summer. Staff and faculty have some limited access to refrigeration and microwave ovens, which facilitates bringing prepared meals from home, although not all are within easy walking distance. Staff tend to work regular hours, with a half-hour lunch break; some essential services, facilities and security staff for example, undertake shifts when food services are closed. Faculty work irregular hours depending upon teaching, research, and service commitments, and are less likely to be present on the campus for consistent blocks of time, and so may have more flexible access to off-campus food sources. While one food alternative existed at the time of the study, a farmers market, the food items were comparatively expensive. It should be noted that UNBC has not, to date, developed a "food strategy" or policy that addresses community f\&n security or any other aspect of food, other than the contract for the company operating the university cafeterias.

3 Tenured faculty have considerable job security; having passed multiple reviews, they can be terminated only under limited circumstances. Tenure-track faculty, striving for tenure, have good job security, but may be terminated if they fail to pass regulated reviews. Senior laboratory instructors are considered permanent appointments, but have lesser job security and are subject to biannual reviews. Contract faculty have no job security. They are hired short-term, contract to contract, carry heavy teaching loads and are very poorly paid in contrast to other faculty. Professional librarians have permanent positions, subject to regular review, with relative job security. 
Other studies (Mammen et al., 2009) indicate that situational factors can influence f\&n security, so the city of Prince George, BC (where the main campus is located), is also a consideration. UNBC is located in the north-central portion of the province, and while Prince George is the largest interior city, it is relatively isolated: most provisions must be imported over considerable distances, affecting food prices and availability. While housing costs are considerably less expensive than larger cities, Prince George experiences long, cold winters with reduced daylight hours, making heating fuel and electricity necessary and significant expenses.

As a final situational factor, UNBC has institutionally recognized (during talks planning for 2015 labor negotiations) that its faculty are among the lowest paid in Canada (personal communication, Faculty Association executive, November 2014), suggesting that faculty might face some financial insecurity in comparison to colleagues at other universities. In 2015 , the salary floor for a lecturer was $\$ 55,393$ annually and for an assistant professor it was $\$ 65,030$. For UNBC staff, financial insecurity is considerably greater. The 2012-2018 CUPE Collective Agreement lists the lowest starting salary as $\$ 30,885$ per year. A staff member must reach a position at level 4 to be paid $\$ 39,457$. As of 2015, Statistics Canada reported that the market basket measure of poverty threshold for a family of four in British Columbia communities with populations of 30,000 to 99,000 (e.g., Prince George) was $\$ 36,446 .{ }^{4}$ A CUPE member who was a single parent of three in an entry-level position in 2015 was well below the Government of Canada's measure of poverty: f\&n security would be a significant concern.

\section{Study methodology}

In this research, UNBC was treated as a case study (Lauckner et al., 2012; Yin, 2003). Case study methods examine "a contemporary phenomenon within its reallife context, especially when the boundaries between the phenomenon and context are not clear" (Yin, 2003, p. 13), and are used when examining questions of process. This study utilized data from multiple sources, including situated local knowledge (the author has been employed by UNBC for over two decades) and focused upon specific situational factors and employee concerns. The Faculty Association, CUPE, and the Exempt group's executive committees supported this research by reviewing and contributing to survey and interview questions, through participation themselves, by promoting member participation in the survey, and through distributing and promoting the results of the research to their membership and others (although they are not responsible for the research). Institutional approval and research ethics for the project was obtained. Anonymity was guaranteed to all participants.

4 Statistics Canada. Market Basket Measure (MBM) thresholds for the reference family by Market Basket Measure region, component and base year. Table 11-10-0066-01. www150.statcan.gc.ca/t1/tbl1/en/tv.action?pid= 1110006601 
Data collection was undertaken in two phases during the 2015 fall semester. Initially, semi-structured interviews were conducted with key informants identified through local knowledge and snowball techniques; this included the staff union executives (the Faculty Association executives declined to participate in this phase), the Women's Centre director, and Wellness Centre counselors, who posted a link on their website and invited their service users to participate. Interview questions focused upon perceived levels of f\&n security and concerns as well as factors creating these concerns, and reported consequences or impacts. Interviews were audio-recorded and analyzed by reviewing recordings and free coding for key themes and ideas.

For the second phase, interview results were used to develop a web-based survey. The survey invitation was emailed to all faculty and staff members utilizing Faculty Association and CUPE/Exempt mailing lists. The survey was active for five weeks with email reminders sent out twice. Survey questions included a range of demographic questions, questions related to participants' perceptions of their relative access to food, personal risk factors, personal and institutional consequences of the lack of easy access to healthy food, as well as options for addressing community f\&n security. Participants were asked to answer a question using closed responses and then were asked if they wished to provide more detail through a follow-up open-ended response option. Sample questions related to f\&n security are included in Table 1.

\section{Table 1. Sample of survey questions related to food and nutritional security}

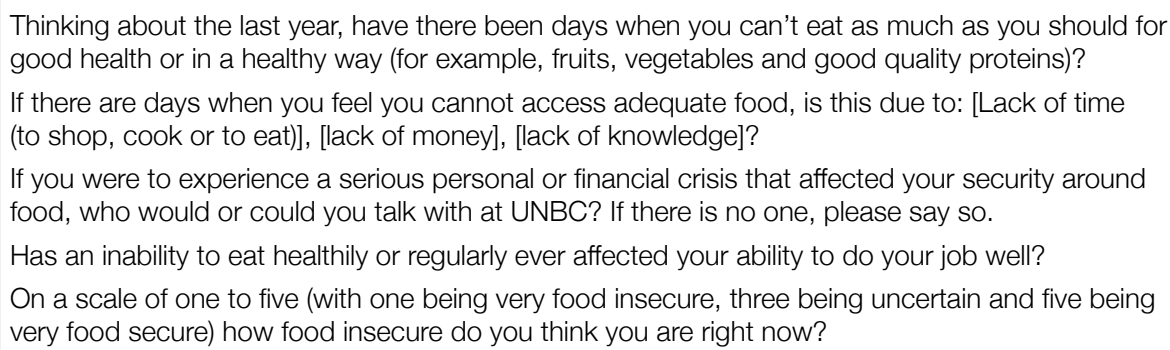

The survey results were analyzed using descriptive statistics and thematic free coding for the open-ended responses (Babbie, 2008). This article does discuss some of the statistical analysis for context; however, it was felt that the voices of the participants were of particular importance in articulating the impacts of poor f\&n security, and in understanding the impact of institutional culture and structures on well-being. These are real people suffering real consequences and their voices are profoundly important in foregrounding this circumstance (often hidden by a statistic). 


\section{Results}

\section{Food and nutritional security challenges among staff}

UNBC has both union and non-union staff; both groups participated in the survey and are reported on collectively (although the non-union group tend to be paid better as their positions are quasi-managerial). Of a possible 392 staff, 131 responded, a response rate of $33.4 \%$. Table 2 summarizes sample demographics.

Table 2. Demographic characteristics of staff (CUPE/Exempt) sample $(n=131)$

\begin{tabular}{|l|l|l|l|l|l|}
\hline Gender & Salary level & Age & Relationship status & $\begin{array}{l}\text { Dependent } \\
\text { children }\end{array}$ & Disability \\
\hline Male: $19 \%$ & Med-High: $67 \%$ & $26-55: 83 \%$ & Spouse/Partner: $70 \%$ & Yes: 38\% & Yes: 9\% \\
\hline Female: $81 \%$ & Low: $33 \%$ & $56+: 11.5 \%$ & Live alone: $30 \%$ & No: $62 \%$ & No: $91 \%$ \\
\hline
\end{tabular}

Access to high-quality and affordable food appears to be a serious concern for UNBC staff. In the survey, food security was defined as having access to sufficient healthy food to maintain good health. While $7 \%$ actually identified as being either very food insecure or food insecure (5\% were uncertain), when asked in another way, 39\% also reported that they cannot eat in a healthy way due to poverty $(15 \%)$ or due to a lack of time (57\%). Gender is an important factor as $8.4 \%$ of all women reported being food insecure as opposed to $4.8 \%$ of all men. Age was also importantparticipants over the age of 36 had higher levels of poor food security. Oddly, staff with permanent positions reported the highest levels of insecurity; $12.5 \%$ for those part-time and $8.4 \%$ for full-time positions. Another anomaly is that those reporting higher salaries also reported the highest level of food concerns $(9.5 \%$ for those with high salaries and $10.8 \%$ for those with moderate salaries in contrast with only $2.9 \%$ with low salaries), demonstrating that poor food security can be related to other factors besides poverty. These challenges produced consequences for the workplace: $13 \%$ of staff reported that being unable to eat well affected their ability to do their job.

Workplace structures and expectations, including time constraints, had significant consequences:

Challenging to eat at work due to lack of area to have food, often eat at desk or do not eat at all until later in day due to meetings or full schedule. (staff)

I often had insufficient time to shop for groceries or visit the University Farmers Market and to cook, and so I did not eat enough, which exacerbated stress. This is more problematic in that I can't afford paying to enter the cafeteria and don't feel that that is the right way to manage a community's relationship with its food. (staff) 
UNBC's restricted on-site food options caused concern among staff who did not have time to prepare food to bring from home.

Food is too high priced for all, held by a monopoly vendor. (staff)

The selection on campus was poor and time did not allow opportunity to seek other sources. (staff)

Many staff believe that low salaries and/or part-time or casual positions contribute to food challenges among their colleagues, with potentially serious consequences.

I have colleagues that are in extremely precarious situations. I have provided food to colleagues on more than one occasion. (staff)

I know there are quite a few members that cannot make it from payday to payday. (staff)

Food costs too much and other financial obligations comes [sic] first. Situationally, we have been running out of vegetables a few days before payday. (staff)

Family obligations can create particular vulnerabilities, both due to low income and time issues.

Some members are single parents in fairly low-paying jobs and their circumstances may not give them the ability to supplement their income ... a large portion of takehome pay is going towards rent, leaving them less income for food. (staff)

To save money I forgo a lot of fruit like berries for example so that my children can have healthier lunches for school and so the food can go further. (staff)

There is no flex time in our office, and working through lunch and going home early or having altered hours has never been discussed, much less offered. I can only come to the conclusion that UNBC simply doesn't care one iota about the health or wellbeing of its staff or their families. (staff)

\section{Food and nutritional security challenges among faculty}

Of a possible 343 UNBC faculty members, 53 completed the survey, a response rate of $15.5 \%$. Of these, $64 \%$ were tenured or in a tenure-track position. Table 3 presents the sample demographic.

Table 3. Demographic characteristics of faculty survey sample $(n=53)$

\begin{tabular}{|l|l|l|l|l|l|}
\hline Gender & Salary level & Age & Relationship status & $\begin{array}{l}\text { Dependent } \\
\text { children }\end{array}$ & Disability \\
\hline Male: $43 \%$ & Med-High: $64 \%$ & $36-55: 71 \%$ & Spouse/Partner: $67 \%$ & Yes: $44 \%$ & Yes: $11 \%$ \\
\hline Female: $56 \%$ & Low: $36 \%$ & $56+: 17 \%$ & Live alone: $33 \%$ & No: $56 \%$ & No: $89 \%$ \\
\hline
\end{tabular}


Of the faculty respondents, $8 \%$ directly identified as being either food insecure or very food insecure. Another $6 \%$ were uncertain. This is a rather surprising level of f\&n security among faculty, given that those rating themselves as food insecure were not contract faculty (assumed to be the most vulnerable), but in permanent positions. There was a gender component: slightly more men (8.6\%) than women (6.7\%) rated themselves as being moderately to severely food insecure. Age was also a factor as $22.2 \%$ of those in the 56-65 years old category stated they were food insecure, compared with $7.1 \%$ of the 36-45 years old faculty. Food security challenges cut across positions as well: $20 \%$ of librarians and $20 \%$ of senior laboratory instructors rated themselves as severely food insecure, while $8.3 \%$ of tenured faculty rated themselves as moderately food insecure. Tenure-track faculty indicated they were generally secure. Unexpectedly, $14.3 \%$ of those who indicated that they were on the high end of the pay scale felt food insecure, as did $11.1 \%$ of those at the mid-level, while half of those at the low end felt food secure.

However, f\&n security has other dimensions: two key factors cited were time constraints and work demands as the largest causes of poor food security among faculty (95\% of respondents).

For the most part, my access to healthy food is quite high. I think time to prepare it properly is the greater issue. (faculty)

Scheduling meal times (lunch in particular) does not seem to be a UNBC priority. (faculty)

Simply time crunch—lack of time to make purchases and limited opportunities on/ near campus to do so. (faculty)

Stressful work conditions, including a sense of overwork, also affect faculty food security.

I have access to healthy foods but my working conditions prevent me from having adequate breaks and time for self-care, including healthy eating and exercise. (faculty)

However, there was also a recognition that some members of the faculty are more financially vulnerable as well.

Very new faculty or [contract faculty] may have a salary inadequate to feed a family. (faculty)

One-income families struggle with cost of bills and providing for families. (faculty)

Overall, $48 \%$ of faculty reported being unable to eat well and $15 \%$ said that this affected their ability to perform their job. 
Finally, as one faculty respondent notes, everyone may be potentially vulnerable to food challenges, as "unforeseen circumstances can occur, potential for homelessness, potential for loss of regularly budgeted money" can happen to everyone. When asked if they had someone they could turn to for assistance in the event of a financial crisis, $42 \%$ indicated that they had no one to turn to for aid. Thus, UNBC's faculty may be as vulnerable to poor food security as more poorly paid staff, if for different reasons. Table 4 compares reasons for poor food security between the two groups.

Table 4. Comparisons of poor food security across groups

\begin{tabular}{|l|c|c|}
\hline & Faculty & Staff \\
\hline Lack of money & $5 \%$ & $15 \%$ \\
\hline Lack of time & $53 \%$ & $57 \%$ \\
\hline Lack of knowledge & $3 \%$ & $2 \%$ \\
\hline
\end{tabular}

\section{Solutions to poor food and nutritional security}

Participants were asked to suggest solutions for addressing poor food security at UNBC as a basis for sustainable community food policies. The solutions tended to address issues of time constraints (by having healthy options easily available) and issues of low income (through ensuring solutions be inexpensive). Interviews and surveys pointed to the need for more diverse, inexpensive, and healthy food options on campus for everyone. It was also noted just how invisible food challenges are for the institution, leading to "hungry ghost" faculty and staff. In ranking possible institutional responses to workplace food security issues, the most popular were expanding existing campus programs that provide fresh, inexpensive food. This included supporting the expansion of the Good Food Box Program (a monthly provision of 20 pounds of local fresh produce for $\$ 20$; with free boxes for those in need) (faculty $45 \%$, staff $34 \%$ ) and the weekly on-campus farmers market (faculty $36 \%$, staff $21 \%$ ). As of 2019 , the farmers market no longer operates, due to a lack of use by the university community.

As an alternative to the for-profit cafeteria, there was moderate support for aiding the student-run coffee shops to sell take-out food items (faculty 26\%, staff 31\%) (they do as of 2019, but the food is costly), or for establishing a community kitchen (faculty $19 \%$, staff $24 \%$ ). Developing a campus food cooperative received strong support (faculty $36 \%$, staff $42 \%$ ). Developing more campus food banks was popular with staff (faculty 17\%, staff 24\%) (the current food bank serves only students). Food banks can, according to the key informants, come with both a stigma for use and difficulty in accessing healthy options via the bank-these issues would need to be taken into account if more sophisticated food banks were used to address campus food security. 
Anonymous registry - posted needs from the UNBC community that can be filled by those who have, and picked up confidentially by those who have not. (faculty)

More private access to food boxes ... there needs to be a level of confidentiality associated with accessing food through the proposed services. (faculty)

I am aware of a co-worker that was extremely worried about her f\&n security during the faculty strike earlier this year. She is a single mom with no family in town and was extremely embarrassed to have to visit the food bank to feed her family. (staff)

Other, creative, options were suggested that both address and acknowledge the institutional workplace context of UNBC as well as the need to address food challenges with a community-minded set of approaches, along with reminders that $\mathrm{UNBC}$ is in the business of education.

Partner with local and regional organizations; greenhouse, food options/types for year-round growth in the northern region; ongoing education and awareness for public and corporations; development of programs for corporations to get involved. Community garden development, break down some of the barriers to these opportunities. (staff)

Education as to cooking, food budgeting (to reduce waste). (staff)

More potlucks and more events that focus around food. (staff)

Workshops, lectures, courses on daily shopping for food with healthy choices and extending the budget to be able to have the healthier choices. (staff)

Food vouchers at campus eateries for those in need for as long as need be. (staff)

It might be useful to access a kitchen where people can come together as group cooking. They get to divide food. (faculty)

Finally, faculty and staff expressed concern about the impact of the for-profit company monopolizing on-campus food services.

As this university is situated so far away from any other sources of food, there should be more options for cheaper food ... Sometimes if I run out of time to make lunch I am stressed out about spending money here on food due to being on a budget. (staff)

UNBC needs food diversity and variety that includes very healthy, whole food options that aren't inaccessible due to cost. This would require a moral investment into options that are not motived by profit margins and corporate policy. (staff)

Cancel or alter the portion of the contract between the university and the cafeteriacatering company that disallows people ... to bring in food from outside. This means the community cannot support small/local businesses. This also contravenes some community/grassroots efforts, for example, if community members cook and bring food to campus to support their friends, even if this is not technically catering, these people are sometimes admonished. (staff) 
In the end both staff and faculty were clear, food and nutritional security is a community concern. The majority from both groups (80-85\%) wanted all potential solutions to food workplace challenges to be available to all members of UNBC, not just the students, supporting a key concept:

Treat food as the centre of our community. (staff)

\section{Discussion and conclusions}

As an indoor biome where we can spend a third of our day (Goetzel \& Ozminkowski, 2008; Stokols, 2018; Wakefield-Rann \& Fam, 2018), a workplace can significantly affect our health and well-being. The place of this study, UNBC, is no exception as the university's structures and work expectations create circumstances where its employees find they are challenged in their ability to eat for best health, confirming some preliminary research suggesting universities are health-threatening workplaces (Mountz, 2016; Parizeau et al., 2016). In this research, faculty and staff wellbeing was threatened by all obstacles to healthy eating (from all causes of poor food security), affecting 39\% of non-instructional staff and $48 \%$ of faculty; levels significantly higher than in the general population of British Columbia where $11.9 \%$ of households face some level of f\&n security (Sriram \& Tarasuk, 2015).

This research has demonstrated that the causes of f\&n security vary across UNBC's populations. Far more faculty than staff identify time constraints and institutional structures as a cause of poor food security rather than poverty. As Mountz (2016) and Parizeau et al. (2016) document, faculty can often feel pressured to put in far more than 35 or 40 hours a week, particularly on the road to tenure and promotion or in hopes of a tenure-track position. If this pressure results in poor $\mathrm{f} \& \mathrm{n}$ security, the impacts to individual and institution are the same as if they were created by poverty. However, a surprising number of UNBC faculty also appear to suffer from financial insecurity, leading to difficulties around healthy eating. Given that faculty often postpone substantially their entry into permanent employment while completing the required advanced degrees, while at the same time acquiring substantial student loans, it would not be surprising that even well-paid (by national median salary standards) faculty may still face challenges around healthy eating.

In contrast, staff clearly suffer from constraints both of time and money due to low salaries, and may be far more vulnerable overall with less power to alter their work circumstances or to argue for better compensation. Whatever the cause, however, in both populations, the consequences affect the entire university community as 13\% of staff and $15 \%$ of faculty believe that they cannot perform at their best as teachers, supporters, or facilitators due to poor food security. This circumstance should raise concern among the UNBC community, especially among the decision-makers. As one staff member notes, "Food insecurity can affect anyone, even those you may 
think would never have to deal with that life challenge." Academic community leaders might need to pay heed to the accuracy of this statement in the interests of broad community well-being.

Poor food security is recognized as creating poor physical and mental health in those experiencing it (Mammen et al., 2009; Tarasuk et al., 2014, 2016; Williams et al., 2012; Woolf et al., 2011). Comments from study participants illuminate what statistics may obscure; the high personal cost of perceived f\&n security for UNBC staff and faculty and the consequences of believing your employer is indifferent. While access to relatively good health care through the employer may offset somewhat the physical impacts of poor access to good food, little offsets the mental and emotional impacts of being, and knowing, you are food insecure (Williams et al., 2012). Further, having to witness colleagues suffer from insecurity can also be troubling, as this study documents.

If the demands of the job undermine personal lives, family lives, and contribute directly to poor f\&n security (food systems demonstrating the interlinkage of institutions, human well-being, and ecosystems (Davila, 2018)), which also affects both personal and family well-being, individuals can find themselves in a very difficult context. A failure of the employer to see the consequences to the larger university community through not addressing the work-life imbalance and institutional contributions to poor access to adequate nutritious food raises pragmatic concerns, as "poor health is associated with reduced employee performance, safety, and morale" (Goetzel \& Ozminkowski, 2008, p. 305). It also raises moral and ethical issues. Is it indeed the obligation of a post-secondary employer to be responsible not just for its acknowledged vulnerable clientele - the students—-but for vulnerable employees as well? Should it consider doing so in the best interests of being a genuine community and for the entirely pragmatic reason that hungry employees cannot do their jobs well? Or should the university care only about one portion of its community and not another (in this case, literally leaving them to starve)? These are questions that institutions should consider within their individual contexts and institutional philosophy, while keeping in mind that universities face greater societal expectation to be models of ethical behavior (Duke, 2019; McNay, 2019; Seligsohn, 2016).

Solutions do exist, outside of the challenge of increasing salary levels and making jobs more secure and long term. As participants in this study have suggested, it is possible to develop community-level responses that might involve reconsideration of facilities (community kitchens, food preparation areas), investing more broadly in food creation or facilitation of access in situ (campus gardens, campus-based food co-ops, reconsideration of food banks, and community-supportive solutions such as a farmers market), or using food as a community-building tool through shared meals. Education through workshops or information provision or collaborative cooking events can assist both food insecure individuals as well as building a stronger sense of community within a university. Fair wage and employment structures must also be 
considered. The relative utility of each solution, however, is contextual within each university, as the faculty and staff of each institution face different circumstances, opportunities and constraints. Within UNBC, for example, fair wages would be important (although a challenge within current fiscal constraints), but reviewing job requirements for better scheduling structures and workload demands are also critical.

A key first step in implementing functional solutions is for institutions themselves to recognize and acknowledge that workplace structures do impact employee health and well-being, and the importance of viewing these impacts as a direct consequence of the institutional ecology and its culture. Indeed, it would be helpful if researchers also recognized these realities, as all previous studies of food security at universities focused solely on the students, ignoring the wider institutional community. If those who teach and support students, particularly vulnerable students, are themselves vulnerable and unable to perform their responsibilities due to poor f\&n security as a component of worker health and well-being, then the mission and purpose of universities are at risk, as is their position as a moral actor within larger society. If we are to teach, learn, and create just and sustainable solutions to societal challenges, universities must start by ensuring their own community of learning is one where all can find security and something healthy to eat. Human ecology theory suggests that in analyzing human ecological systems, we must examine the social and ethical dimensions of such systems by asking, "are they fair or ethical?" Dyball and Carlsson (2017) suggest that the study of human ecology posits that the attainment of an institution or a world that is

just, sustainable and worthwhile ... is a collective effort with unavoidable political challenges to overcoming entrenched barriers, including those that involve disparities of power, as well as those arising from the underlying cultural values ("paradigms") that legitimize everyday assumptions about what constitutes normal, everyday behavior. (p. 26)

Finally, beyond philosophy, supporting the health of its employees does, in the long run, support the health of the institution (Goetzel \& Ozminkowski, 2008). Thus, addressing these academic "hungry ghosts" - present but rarely visible to academic decision-makers_-feeds many needs and members of a university.

\section{Acknowledgments}

Funding for this study was provided by a University of Northern British Columbia Office of Sustainability Green Grant. The author thanks Melanie Anderson, the undergraduate research assistant on the project, for her contributions. The author also thanks those academic staff and faculty who took the time to participate in this research. 


\section{References}

Babbie, E. R. (2008). The basics of social research. Thomson Wadsworth.

Booth, A. L., \& Anderson, M. (2017). Food (in)security within a university community: The experiences of students, staff and faculty at a sustainable institution. In W. L. Filho, L. Brandli, J. Newman, \& P. Castro (Eds.), Handbook of theory and practice of sustainable development in higher education (pp. 187-200). Springer International Publishing. doi.org/ 10.1007/978-3-319-47868-5_12

Cady, C. L. (2014). Food insecurity as a student issue. Journal of College and Character, 15(4), 265-272.

Canadian Federation of Students-Ontario. (2012). Final report-Task force on campus food services. Canadian Federation of Students-Ontario. cfsontario.ca/wp-content/uploads/ 2017/07/CFS-2013FoodReport.pdf

Chaparro, M. P., Zaghloul, S. S., Holck, P., \& Dobbs, J. (2009). Food insecurity prevalence among college students at the University of Hawaii at Manoa. Public Health Nutrition, 12(11), 2097-2103. doi.org/10.1017/s1368980009990735

Davila, F. (2018). Human ecology and food systems: Insights from the Philippines. Human Ecology Review, 24(1), 23-49. doi.org/10.22459/her.24.01.2018.02

Duke, C. (2019). How central is the "principal mission" of the university today? In W. Archer \& H. G. Schuetze (Eds.), Preparing students for life and work: Policies and reforms affecting higher education's principal mission. Brill. doi.org/10.1163/9789004393073_001

Dyball, R., \& Carlsson, L. (2017). Ellen Swallow Richards: Mother of human ecology? Human Ecology Review, 23(2), 17-28. doi.org/10.22459/her.23.02.2017.03

El Zein, A. (2017). Socio-demographic correlates and predictors of food insecurity among first year college students. Journal of the Academy of Nutrition and Dietetics, 117(10), A146. doi.org/10.1016/j.jand.2017.08.102

Farahbakhsh, J., Ball, G. D. C., Farmer, A. P., Maximova, K., Hanbazaza, M., \& Willows, N. (2015). How do student clients of a university-based food bank cope with food insecurity? Canadian Journal of Dietetic Practice and Research, 76(4), 200-203. doi.org/10.3148/ cjdpr-2015-020

Frank, L. (2018). "Hungry for an education": Prevalence and outcomes of food insecurity among students at a primarily undergraduate university in rural Nova Scotia. Canadian Journal of Higher Education, 48(2), 109-129. doi.org/10.7202/1057106ar

Gaines, A., Robb, C. A., Knol, L. L., \& Sickler, S. (2014). Examining the role of financial factors, resources and skills in predicting food security status among college students. International Journal of Consumer Studies, 38(4), 374-384. doi.org/10.1111/ijcs.12110 
Goetzel, R. Z., \& Ozminkowski, R. J. (2008). The health and cost benefits of work site health-promotion programs. Annual Review of Public Health, 29, 301-323. doi.org/ 10.1146/annurev.publhealth.29.020907.090930

Hanna, L. A. (2014). Evaluation of food insecurity among college students. American International Journal of Contemporary Research, 4(4), 46-49.

Hughes, R., Serebryanikova, T., Donaldson, K., \& Leveritt, M. (2011). Student food insecurity: The skeleton in the university closet. Nutrition and Dietetics, 68(1), 27-32. doi.org/10.1111/j.1747-0080.2010.01496.x

Lauckner, H., Paterson, M., \& Krupa, T. (2012). Using constructivist case study methodology to understand community development processes: Proposed methodological questions to guide the research process. The Qualitative Report, 17(13), 1-22.

Mammen, S., Bauer, J. W., \& Richards, L. (2009). Understanding persistent food insecurity: A paradox of place and circumstance. Social Indicators Research, 92, 151-168. doi.org/ $10.1007 / s 11205-008-9294-8$

Martinez, S. M., Frongillo, E. A., Leung, C., \& Ritchie, L. (2018). No food for thought: Food insecurity is related to poor mental health and lower academic performance among students in California's public university system. Journal of Health Psychology. Advance online publication. doi.org/10.1177/1359105318783028

McArthur, L. H., Ball, L., Danek, A. C., \& Holbert, D. (2018). High prevalence of food insecurity among university students in Appalachia reflects a need for educational interventions and policy advocacy. Journal of Nutrition Education and Behavior, 50(6), 564-572. doi.org/10.1016/j.jneb.2017.10.011

McIntyre, L., Bartoo, A. C., \& Emery, J. C. H. (2012). When working is not enough: Food insecurity in the Canadian labour force. Public Health and Nutrition, 17(1), 49-57. doi.org/10.1017/s1368980012004053

McNay, I. (2019). Governance, leadership and university cultures: Do universities critique social norms and values, or copy them? In P. Gibbs, J. Jameson, \& A. Elwick (Eds.), Values of the university in a time of uncertainty. Springer. doi.org/10.1007/978-3-03015970-2_7

Meldrum, L. A., \& Willows, N. D. (2006). Food insecurity in university students receiving financial aid. Canadian Journal of Dietetic Practice and Research, 67(1), 43-46. doi.org/ $10.3148 / 67.1 .2006 .43$

Micevski, D. A., Thornton, L. E., \& Brockington, S. (2014). Food insecurity among university students in Victoria: A pilot study. Nutrition and Dietetics, 71(4), 258-264. doi.org/10.1111/1747-0080.12097

Mountz, A. (2016). Women on the edge: Workplace stress at universities in North America. The Canadian Geographer, 60(2), 205-218. doi.org/10.1111/cag.12277 
Munro, N., Quayle, M. L., Simpson, H., \& Barnsley, S. (2013). Hunger for knowledge: Food insecurity among students at the University of KwaZulu-Natal. Perspectives in Education, 31(4), 168-179.

Parizeau, K., Shillington, L., Hawkins, R., Sultana, F., Mountz, A., Mullings, B., \& Peake, L. (2016). Breaking the silence: A feminist call to action. The Canadian Geographer, 60(2), 192-204. doi.org/10.1111/cag.12265

Patton-Lopez, M. M., Lopez-Cevallos, D. F., Cancel-Tirado, D. I., \& Vazquez, L. (2014). Prevalence and correlates of food insecurity among students attending a midsize rural university in Oregon. Journal of Nutrition Education and Behavior, 46(3), 209-214. doi.org/10.1016/j.jneb.2013.10.007

Payne-Sturges, D. C., Tjaden, A., \& Caldeira, K. M. (2018). Student hunger on campus: Food insecurity among college students and implications for academic institutions. American Journal of Health Promotion, 32(2), 349-35. doi.org/10.1177/0890117117719620

Seligsohn, A. J. (2016). Colleges and universities as exemplars in the development of citizens. Journal of College and Character, 17(1), 1-7. doi.org/10.1080/2194587X.2015.1125369

Sriram, U., \& Tarasuk, V. (2015). Changes in household food insecurity rates in Canadian metropolitan areas from 2007 to 2012. Canadian Journal of Public Health, 106(5), 322327. doi.org/10.17269/cjph.106.4893

Stokols, D. (2018). The changing morphology of indoor ecosystems in the twenty-first century driven by technological, climatic, and sociodemographic forces. Human Ecology Review, 24(2), 25-40. doi.org/10.22459/her.24.02.2018.02

Tarasuk, V., Mitchell, A., \& Dachner, N. (2014). Household food insecurity in Canada, 2012. Food Insecurity Policy Research (PROOF). proof.utoronto.ca/wp-content/ uploads/2014/05/Household_Food_Insecurity_in_Canada-2012_ENG.pdf

Tarasuk, V., Mitchell, A., \& Dachner, N. (2016). Household food insecurity in Canada, 2014. Food Insecurity Policy Research (PROOF). proof.utoronto.ca/wp-content/uploads/ 2016/04/Household-Food-Insecurity-in-Canada-2014.pdf

Wakefield-Rann, R., \& Fam, D. (2018). Initiating a transdisciplinary conversation to improve indoor ecologies. Human Ecology Review, 24(2), 3-23. doi.org/10.22459/her. 24.02.2018.01

Watson, T. D., Malan, H., Glik, D., \& Martinez, S. M. (2017). College students identify university support or basic needs and life skills as key ingredient in addressing food insecurity on campus. California Agriculture, 71(3), 130-138. doi.org/10.3733/ ca. $2017 \mathrm{a} 0023$

Williams, P. L., MacAulay, R. B., Anderson, B. J., Barro, K., Gillis, D. E., Johnson, C. P., Langille, L. L., Moran, S., \& Reimer, D. E. (2012). "I would have never thought that I would be in such a predicament": Voices from women experiencing food insecurity in Nova Scotia, Canada. Journal of Hunger and Environmental Nutrition, 7(2-3), 253-270. doi.org/10.1080/19320248.2012.704740 
Woolf, S. H., Dekker, M. M., Byrne, F. R., \& Miller, W. D. (2011). Citizen-centered health promotion: Building collaborations to facilitate healthy living. American Journal of Preventative Medicine, 40(1), IS1, S38-S47. doi.org/10.1016/j.amepre.2010.09.025

Yin, R. K. (2003). Case study research: Design and methods. Sage. 
This text is taken from Human Ecology Review, Volume 25, Number 2, 2019, published by ANU Press, The Australian National University, Canberra, Australia. doi.org/10.22459/HER.25.02.2019.06 